\title{
Research and Application of Water Flooding Timing and Method for Blocky Bottom Water Fractured Buried Hill Reservoir
}

\author{
Xiaolin Zhu, Hui Cai, Xinran Wang, Qin Zhu, Zhiqiang Meng \\ Tianjin Branch of CNOOC (China) Limited, Tianjin, China \\ Email: zhuxl4@cnooc.com.cn
}

How to cite this paper: Zhu, X.L., Cai, H., Wang, X.R., Zhu, Q. and Meng, Z.Q. (2019) Research and Application of Water Flooding Timing and Method for Blocky Bottom Water Fractured Buried Hill Reservoir. Journal of Power and Energy Engineering, 7, 1-10.

https://doi.org/10.4236/jpee.2019.79001

Received: August 15, 2019

Accepted: September 15, 2019

Published: September 18, 2019

Copyright $\odot 2019$ by author(s) and Scientific Research Publishing Inc. This work is licensed under the Creative Commons Attribution International License (CC BY 4.0).

http://creativecommons.org/licenses/by/4.0/

c. (i) Open Access

\begin{abstract}
Oilfield A is a fractured buried hill reservoir in Bohai bay of China. In order to solve the difficult problem of water flooding timing and method in oilfield. Considering the characteristics of the buried hill fractures with stress sensitivity and strong heterogeneity, the ECLIPSE software was used in the research, and a three-dimensional injection-production numerical model for horizontal wells in buried hill reservoirs is established. According to the main research factors in water flooding, a series of water flooding schemes are designed, and the optimization of water flooding timing, oil recovery rate and water flooding mode in buried hill reservoirs were carried out. The results show that the optimum pressure level of fractured reservoir is about $70 \%$ of the original reservoir pressure. The optimal water flooding method is the conventional water flooding in the initial stage, when the water cut reaches $80 \%$, it is converted into periodic water flooding. The oil recovery is the highest when the water injection period is 4 months. Field tests show that conventional water flooding is carried out in the initial stage of the oilfield A when the pressure is reduced to $70 \%$ of the original. Periodic water flooding is carried out when water cut is $80 \%$. Good development results had been achieved in the 10 years since oilfield $\mathrm{A}$ was put into production. The average productivity of single well reached $300 \mathrm{~m}^{3} / \mathrm{d}$ in the initial stage, at present, the water cut is $60 \%$, and the recovery degree is $18.5 \%$, which is better than that of similar oilfields. This technology improves the water flooding effect of blocky bottom water fractured dual media reservoirs in metamorphic buried hills, and provides a reference for the development of similar reservoirs.
\end{abstract}

\section{Keywords}

Fractured Buried Hill Reservoir, Water Flooding Timing, 
Water Flooding Method, Numerical Simulation

\section{Introduction}

Fractured reservoirs have the characteristics of crack development, strong heterogeneity, complex reservoir and seepage laws, which make it difficult to develop such reservoirs [1]-[8]. Stress sensitivity exists in fractured reservoirs. Because of the existence of stress sensitivity, with the decrease of formation pressure in the development process, the volume of matrix and fracture is reduced, and the seepage capacity of fractured reservoir is reduced accordingly. How to effectively control the influence of this unfavorable factor on development effect is the key to formulate development strategy [9]-[15]. At present, worldwide scholars have studied the porosity and permeability of fractured reservoirs with effective stress and stress sensitivity evaluation methods and standards through rock stress sensitivity experiments [16]-[22]. However, there are few studies on stress sensitivity and water injection timing and mode in fractured reservoirs. Therefore, this paper takes oilfield A fractured reservoir in Bohai bay as an example. The reasonable water injection timing and mode of fractured reservoir in the presence of stress sensitivity are studied by reservoir numerical simulation technology. It will ultimately guide the actual production of the mine.

\section{General Situation of Oilfield}

The metamorphic buried hill fractured reservoir in oilfield A is located in the mid-north section of Liaoxi low uplift. It is the largest metamorphic fractured reservoir invested in Bohai Oilfield at present [23] [24] [25] [26]. The main producing layer is Archean metamorphic buried hill, the buried depth of the reservoir is $1700-1900 \mathrm{~m}$, and the longitudinal span is as high as $200 \mathrm{~m}$. The lithology is mainly biotite gneiss and plagioclase gneiss, and the reservoir type is pore-fracture. The regional structural fractures are mainly middle-high angle $\left(20^{\circ}-60^{\circ}\right)$ fractures. The main trend of fractures is northeast-southwest, and the following is northwest-southeast. The fracture density is $0.5 \leq 3.5$ cracks per meter. The porosity of matrix and fracture is $5.72 \%$ and $1.08 \%$, respectively, and

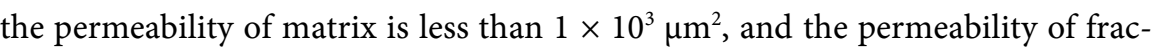
ture is $260-900 \times 10^{3} \mu^{2}$. Its reservoir type is double porosity reservoir with block weak bottom water, and the lithology mainly consists of light gray gneiss and its broken rocks. In the reservoir, water injection wells are spaced near oil-water contact in time, and a new top-bottom interlaced 3D injection-production well deployment mode is formed, that is oil production on top and water injection at bottom. In the early stage of production, depletion development was adopted. After one year of production, the formation pressure decreased rapidly, which confirmed that the bottom water was weak. In order to supply formation energy and prevent fracture closing, it is urgent to carry out reasonable research on water injec- 
tion time and water injection mode to solve the dual contradiction of "pressure maintenance" and "water reduction" in buried hill fracture reservoir.

\section{Research on Numerical Simulation}

\subsection{Establishment of Geological Model}

Equivalent numerical model was established by using ECLIPSE software. The model is a media with dual porosity and single permeability, and its grid number is $25 \times 25 \times 50=31,250$. The $1-25$ layers of $\mathrm{z}$-direction represent the matrix system part, the 26 - 50 layers represent the crack part, and the grid length is 1 $\mathrm{cm} \times 1 \mathrm{~cm} \times 1 \mathrm{~cm}$. There is one injection well at the bottom of the model and two production wells at the top, and they are all horizontal wells (Figure 1).

\subsection{Research on Reasonable Time of Water Injection and Pressure Maintenance}

For fractured reservoirs, it is necessary to supply the formation energy for maintaining high formation pressure and large production pressure difference and preventing cracks deformation and closure, resulting in a decrease in oil production index, usually using artificial energy to maintain pressure in the process of development. The main driving forces in the water flooding process are the water injection pressure gradient, capillary force and gravity. However, for fracture systems and matrix systems, the three driving forces have different effects. For the crack system, especially for the reservoir with high original oil saturation, the main driving force is the water injection pressure gradient in the water injection and oil production process, and its flow condition is in accordance with Darcy's law, and the capillary pressure is small or the capillary pressure can be neglected. Besides, the water drive efficiency can reach more than $95 \%$. For the matrix system, the water flooding target is the crude oil in the small pores and small cracks of the matrix rock. During the driving process, the primary driving force is

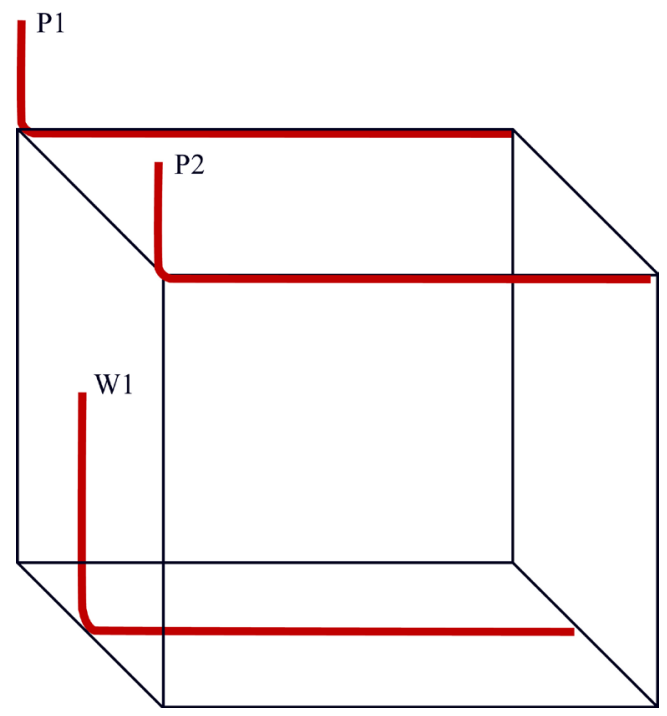

Figure 1. Numerical simulation model. 
capillary force that makes the water in the crack enter the matrix rock, so that the oil in matrix rock can be drained. And the secondary driving force is the flowing pressure gradient between crack system and matrix system. It can be noted that the fractured reservoir has a strong fluid-solid coupling effect in the water flooding process. In order to reduce the permeability and oil well productivity loss caused by the formation pressure drop, low permeability fractured reservoirs can be mined by early or advanced water injection. But, for high-permeability fractured reservoirs, early or advanced water injection is easy to cause violent flooding, which leads to poor development effect. Therefore, it is necessary to carry out reasonable research on water injection time and pressure maintenance.

In order to optimize the timing of water flooding and the ratio of injection to production, the water flooding is started when the reservoir pressure drops to $100 \%, 90 \%, 80 \%, 70 \%, 60 \%$ and $50 \%$ of the original pressure, and calculate the relevant parameters such as in the same water cut and the same production period the degree of recovery and the utilization rate of the injected water at different water flooding timings. It can be seen that with the delay of water flooding time, the degree of recovery in the same production period shows a downward trend (Figure 2). This is because, with the delay of water flooding, the reservoir pressure drops. Due to the presence of stress sensitivity, the effective permeability of cracks and matrix decreases, the conductivity of fractures decreases, the production capacity decreases, the production of oil wells decreases, and the degree of recovery of reservoirs decreases. In terms of water flooding efficiency (Figure 3), the water flooding utilization rate is increasing with the delay of water flooding timing. This is because the decrease in oil well production leads to a decrease in water cut in the well and a slower rate of increase in water cut. In the same production period, the pressure level is kept at a low level to improve the utilization rate of the injected water to some extent. Under the same water cut condition, the recovery degree of the reservoir increases with the decrease of pressure level before degassing of the formation crude oil, but after degassing, the degree of recovery decreases. Before the degassing, the pressure level is kept at a low level. Due to the sensitivity of the crack stress, the oil recovery rate is lower, and the matrix infiltration can be more fully exerted, resulting in an increase in the recovery of the well at the same water cut. However, after degassing, the flow resistance of the fluid in the pores increases due to the three-phase percolation, and the porous flow of the oil in the pores become more difficult, resulting in a decrease in the recovery of the crude oil. From the mining life under the limit water cut, we can see that maintaining the pressure level at a lower level will increase the production life of the oilfield to a greater extent (Figure 4) and reduce the economic benefits of the reservoir. Considering the above factors comprehensively, for fractured buried hill reservoirs, the pressure level cannot be maintained at a high level to ensure sufficient imbibition action and prevent premature flooding of the oil well, resulting in poor development of the reservoir. It cannot be maintained at a very low level. On the one hand, the three-phase 




Figure 2. The relationship between the degree of production and the timing of water injection at the same time.

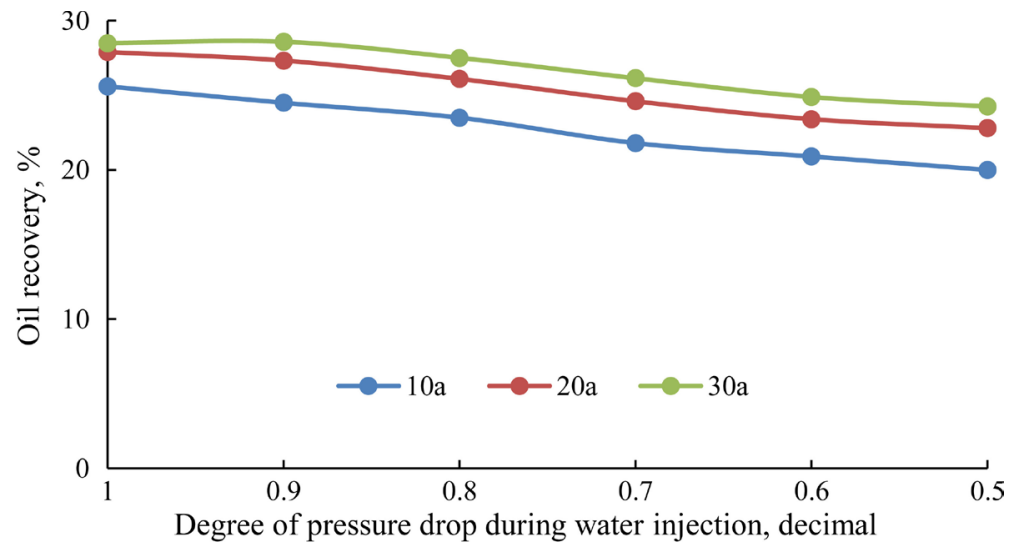

Figure 3. Injecting water utilization rate and timing at the same time.

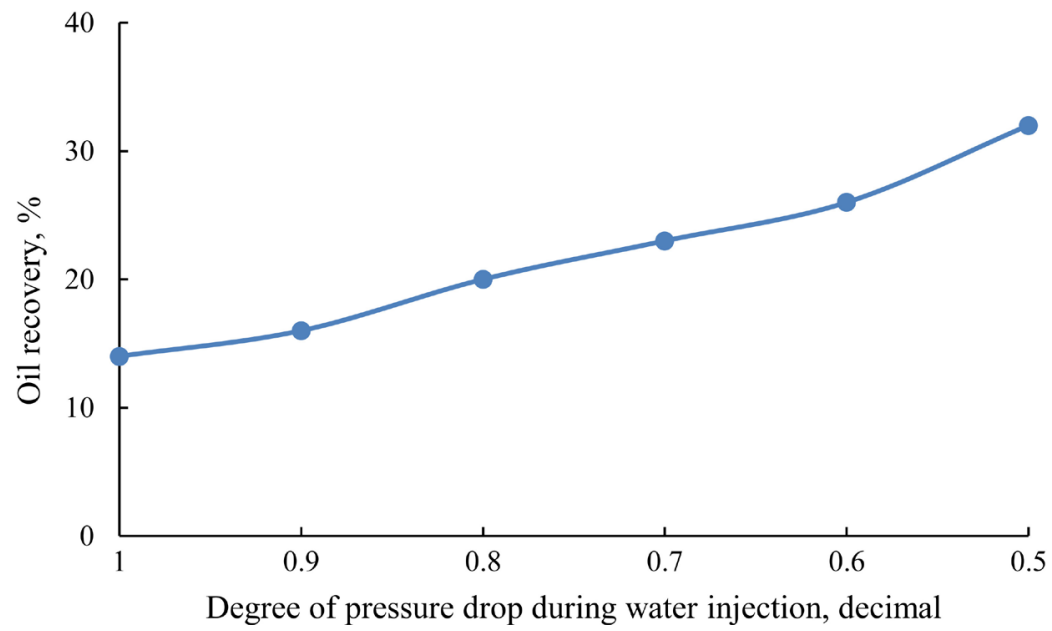

Figure 4. The relationship between the mining life and the timing of water injection under the limit water cut.

seepage caused by degassing prevents the oil from seeping resistance increase, and on the other hand prevents the crack permeability from decreasing due to stress sensitivity, which in turn leads to a decrease in oil well productivity, and in 
a significant extension of the reservoir development period and reduced the development effect of the oilfield. It is finally recommended that the timing and pressure of the water injection in the oilfield $\mathrm{A}$ be kept at an optimum value of about $70 \%$ of the original reservoir pressure.

\subsection{Research of Reasonable Water Flooding Method}

Unstable water flooding is a common water flooding method in fractured reservoirs, including periodic water flooding, pulse water flooding and asynchronous water flooding. The role of unstable water flooding is to redistribute the pressure of different permeability media at different speeds by changing the amount of water injected or the amount of liquid produced. Due to the variability in pressure redistribution, a vertical pressure gradient that causes fluid flow is established between the sandstone layers and between the fractures of the buried hill reservoir and the matrix rock mass. At the same time, during the unstable distribution of pressure, the balance of capillary force is destroyed, and the heterogeneity of the hydrophilic oil layer produces capillary convection conditions in which oil and water flow in opposite directions. Therefore, it can be said that the essence of unstable water flooding is to make full use of the internal and external natural energy of the reservoir, and fully exert the combined effects of driving pressure, elastic force, gravity and capillary force to improve the production potential of the middle and low permeability layers and rock blocks, and Thereby improving the overall development of the reservoir.

In order to optimize the best water injection method, three kinds of water injection modes are designed, namely, conventional water flooding, asynchronous water flooding and periodic water flooding. Calculating the oil recovery of each method under the condition that the water cut is limited to $98 \%$, the results are shown in Figure 5. It can be seen that, compared with conventional water flooding, both asynchronous water flooding and periodic water flooding can improve the oil recovery to a certain extent, And periodic water flooding can improve oil recovery more greatly. But compared with conventional water

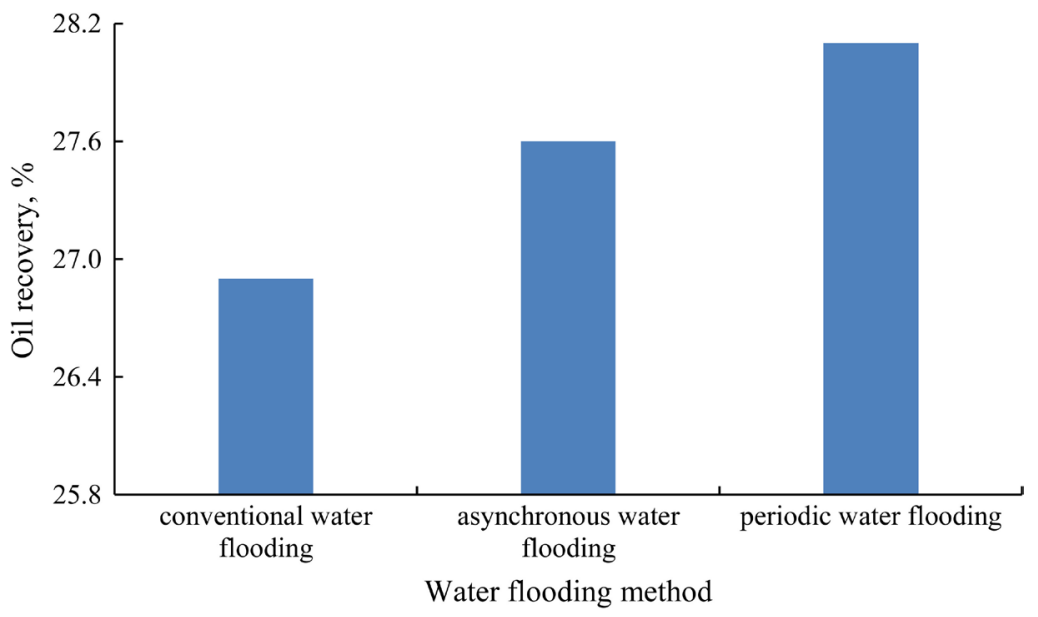

Figure 5. The relationship between oil recovery and water flooding method. 
flooding, periodic water flooding and asynchronous water flooding can prolong reservoir development time, especially asynchronous water flooding. Through numerical simulation, it is found that the development life of asynchronous water flooding is 1.4 times longer than conventional water flooding. Therefore, in order to improve the oil recovery of oilfield $\mathrm{A}$, it is suggested the water flooding method is turned to periodic water flooding at the later stage of development.

Generally speaking, the earlier the periodic water flooding is carried out, the greater the degree of enhancing oil recovery is. However, it is obviously inappropriate to adopt this method prematurely because periodic water flooding will prolong the development life of oilfields. In order to optimize the timing of turning into periodic water flooding, when the water cut is $60 \%, 70 \%, 80 \%$ and $90 \%$ respectively, the schemes of turning into periodic water flooding are set, and the oil recovery of different schemes are calculated when the water cut reached the limit of $98 \%$ respectively. The results are shown in Figure 6. It can be seen, the oil recovery is the highest when turning into periodic water flooding at the timing of water cut reaches $80 \%$.

The bigger the pressure drop of periodic water flooding method is, the better the effect of increasing oil production is. But if the pressure drop in the first period is too large, the oil production decline in the next period will be increased, and the oil recovery increment per unit pressure drop will be reduced, especially in fractured reservoirs, if the pressure drop is too large, the fracture opening will be reduced or even closed, which will lead to the decrease of fracture permeability and the decline of oil well productivity, therefore, reasonable interval of periodic water flooding is also very important for this method to improve reservoir recovery. Figure 7 shows the relationship between oil recovery and time interval of periodic water flooding in different periods. It can be seen that the oil recovery is the highest when the time interval of periodic water flooding is 2 months. The main reason is that the time interval mainly affects the speed of pressure drop. For oilfield A, the numerical simulation shows that after adjusting the working system of injection wells, the time of pressure wave propagating from the bottom of injection wells to the bottom of production wells is about 2 months. If

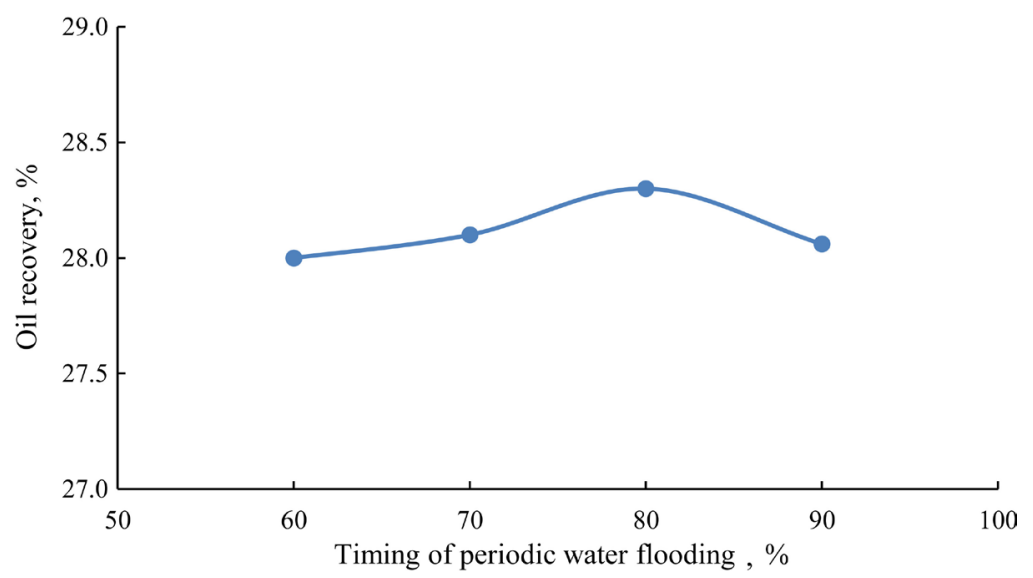

Figure 6. The relationship between oil recovery and the timing of periodic water flooding. 




Figure 7. The relationship between oil recovery and time interval of periodic water flooding.

the time interval exceeds 2 months, the oil production of production wells will be greatly reduced. Therefore, the development effect is the best when the injection time interval of periodic water flooding is 2 months. Therefore, the optimum water injection period for oilfield $\mathrm{A}$ is 4 months, which means water flooding for 2 months and suspension for 2 months in a period.

\section{Application Effect}

Oilfield A is located in Liaodong Bay. The main reservoir belongs to Archaean metamorphic buried hill, which is a typical dual medium reservoir. Logging data and core data show that the fracture development degree in the reservoir varies greatly in both horizontal and vertical directions, and the reservoir shows strong heterogeneity.

This oilfield was put into production in December 2009. Blocks (2/7 block and 5 blocks) that are put into production in advance adopt depletion development method in the early stage, production wells presents the development characteristics of high initial production rate but large production decline. After 2 years of production, formation pressure drops to $70 \%$ and conventional water flooding was carried out. In 2014, the periodic water flooding field test was carried out for the first time in 2/7 block, interval time of periodic water flooding was 2 to 3 months. Up to now, cumulative oil production is $8.9 \times 10^{4} \mathrm{~m}^{3} / \mathrm{a}$ and the water cut is reduced by $7.2 \%$ in $2 / 7$ block by periodic water flooding.

\section{Conclusions}

1) For the fractured reservoirs, matrix system is the major reservoir storage space, and the production of crude oil in matrix system mainly depends on imbibition, increasing the recovery of matrix system is the key to the development of fractured reservoirs efficiently.

2) When the reservoir pressure level of fractured reservoir keeps decreasing to about $70 \%$ of the original reservoir pressure, the water flooding development effect is the best. 
3) The optimum water injection method for fractured reservoirs is conventional water flooding in early stage, and conversion to periodic water flooding when water cut reaches $80 \%$. The period of water flooding is 4 months, including water flooding for 2 months and suspension for 2 months in a period.

\section{Acknowledgements}

This project is supported by National Science and Technology Major Project foundation of China in the 13th Five Year Plan. Fund No. 2016ZX05058-001.

\section{Conflicts of Interest}

The authors declare no conflicts of interest regarding the publication of this paper.

\section{References}

[1] Ullah, S., Shen, Y.T., Mobarak, S.A., et al. (1988) Development Feasibility Study: Dongshengpu Buried Hill Reservoir. International Meeting on Petroleum Engineering, Tianjin, 1-4 November 1988. https://doi.org/10.2523/17577-MS

[2] Witherspoon, P.A., Amick, C.H., Gale, J.E. and Iwai, K. (1979) Observations of a Potential Size Effect in Experimental Determination of the Hydraulic Properties of Fractures. Water Resources Research, 15, 1142-1146.

https://doi.org/10.1029/WR015i005p01142

[3] Konzuk, J.S. and Kueper, B.H. (2004) Evaluation of Cubic Law Based Models Describing Single-Phase Flow through a Rough-Walled Fracture. Water Resources Research, 40, W02402. https://doi.org/10.1029/2003WR002356

[4] Brown, S.R. (1987) Fluid Flow through Rock Joints: The Effect of Surface Roughness. Journal of Geophysical Research, 92, 1337-1347. https://doi.org/10.1029/JB092iB02p01337

[5] Marica, F., Chen, Q., Hamilton, et al. (2006) Spatially Resolved Measurement of Rock Core Porosity. Journal of Magnetic Resonance, 178, 136-141. https://doi.org/10.1016/j.jmr.2005.09.003

[6] Guerreiro, V., Mazzoli, S., Iannace, A., et al. (2013) A Permeability Model for Naturally Fractured Carbonate Reservoirs. Marine and Petroleum Geology, 40, 115-134.

[7] Mur, A., Purcell, C., Soong, Y., et al. (2011) Integration of Core Sample Velocity Measurements into a 4D Seismic Survey and Analysis of SEM and CT Images to Obtain Pore Scale Properties. Energy Procedia, 4, 3676-3683.

[8] Avid, B., Sato, S., Takanohashi, T. and Saito, I. (2004) Characterization of Asphaltenes from Brazilian Vacuum Residue Using Heptane-Toluene Mixtures. Energy Fuels, 18, 1792-1797. https://doi.org/10.1021/ef049960n

[9] Crandall, D., Bromhal, G. and Karpyn, Z.T. (2010) Numerical Simulations Examining the Relationship between Wall-Roughness and Fluid Flow in Fractures. International Journal of Rock Mechanics and Mining Sciences, 47, 784-796. https://doi.org/10.1016/j.ijrmms.2010.03.015

[10] Zimmerman, R.W. and Bodvarsson, G.S. (1996) Hydraulic Conductivity of Rock Fractures. Transport in Porous Media, 23, 1-30. https://doi.org/10.1007/BF00145263

[11] Setiawan, A., Nomura, H. and Suekane, T. (2012) Microtomography of Imbibition 
Phenomena and Trapping Phenomena. Transport in Porous Media, 92, 243-257. https://doi.org/10.1007/s11242-011-9899-2

[12] Durham, W.B., Bourcier, W.L. and Burton, E.A. (2001) Direct Observation of Reactive Flow in a Single Fracture. Water Resources Research, 37, 1-12. https://doi.org/10.1029/2000WR900228

[13] Gouze, P., Noiriel, C., Bruderer, C., Loggia, D. and Leprovost, R. (2003) X-Ray Tomography Characterization of Fracture Surfaces during Dissolution. Geophysical Research Letters, 30, 1267. https://doi.org/10.1029/2002GL016755

[14] Pyrak-Nolte, L.J., Cook, N.G.W. and Nolte, D.D. (1988) Fluid Percolation through Single Fractures. Geophysical Research Letters, 15, 1247-1250. https://doi.org/10.1029/GL015i011p01247

[15] Noiriel, C., Luquot, L., Madé, B., et al. (2009) Changes in Reactive Surface Area during Limestone Dissolution: An Experimental and Modelling Study. Chemical Geology, 265, 160-170. https://doi.org/10.1016/j.chemgeo.2009.01.032

[16] Wilson, T.H., Wells, A., Peters, D., et al. (2012) Fracture and 3D Seismic Interpretations of the Fruitland Formation and Cover Strata: Implications for $\mathrm{CO}_{2}$ Retention and Tracer Movement, San Juan Basin Pilot Test. International Journal of Coal Geology, 99, 35-53. https://doi.org/10.1016/j.coal.2012.02.007

[17] Zimmerman, R.W., Chen, D.W. and Cook, N.G.W. (1992) The Effect of Contact Area on the Permeability of Fractures. Journal of Hydrology, 139, 79-96. https://doi.org/10.1016/0022-1694(92)90196-3

[18] Witherspoon, P.A., Wang, J.S.Y., Iwai, K. and Gale, J.E. (1980) Validity of Cubic Law for Fluid Flow in Deformable Rock Fracture. Water Resources Research, 16, 1016-1024. https://doi.org/10.1029/WR016i006p01016

[19] Berkowitz, B. and Scher, H. (1995) On Characterization of Anomalous-Dispersion in Porous and Fractured Media. Water Resources Research, 31, 1461-1466. https://doi.org/10.1029/95WR00483

[20] Zhu, T., Ogbe, D.O. and Khataniar, S. (2004) Improving the Foam Performance for Mobility Control and Improved Sweep Efficiency in Gas Flooding. Industrial \& Engineering Chemistry Research, 43, 4413-4421. https://doi.org/10.1021/ie034021o

[21] Blunt, M.J., King, M.J. and Harvey, S. (1992) Simulation and Theory of Two-Phase Flow in Porous Medium. Physical Review A, 46, 7680-7699. https://doi.org/10.1103/PhysRevA.46.7680

[22] Szymkiewicz, A. (2013) Upscaling from Darcy Scale to Field Scale. In: Modelling Water Flow in Unsaturated Porous Media. GeoPlanet. Earth and Planetary Sciences, Springer, Berlin, Heidelberg, 139-175. https://doi.org/10.1007/978-3-642-23559-7_5

[23] Tong, K.J., Liu, H.Q., Zhang, Y.C., et al. (2015) Three-Dimensional Physical Modeling of Water flooding in Metamorphic Fractured Reservoirs. Petroleum Exploration and Development, 42, 538-544. https://doi.org/10.1016/S1876-3804(15)30054-9

[24] Tong, K.J., Li, B., Dai, W.H., et al. (2017) Sparse Well Pattern and High-Efficient Development of Metamorphic Buried Hills Reservoirs in Bohai Sea Area, China. Petroleum Exploration and Development, 44, 590-599.

[25] Zhu, X.L., Ge, L.Z., Meng, Z.Q., et al. (2019) Efficient Development Technology of Narrow Oil Rim with Gas Cap and Edge Water \& Its Practice. Oil Drilling \& Production Technology, 41, 71-76.

[26] Fang, N., Liu, Z.B., Lv, Z.B., et al. (2018) Gas Channeling Pattern and Full-Life Development Strategy for Oil Reservoir with Large Gas-Cap. Special Oil \& Gas Reservoirs, 25, 117-121. 